\title{
Fire Emergency Safety Preparedness in the College of Leadership Development Studies Building in Covenant University, Ota, Nigeria
}

\author{
Sholanke Anthony Babatunde, Ajonye George Oche*, Okpanachi Paul \\ Department of Architecture, Covenant University, Ota, 112212, Ogun State, Nigeria
}

Received July 30, 2020; Revised October 15, 2020; Accepted October 24, 2020

\begin{abstract}
Cite This Paper in the following Citation Styles
(a): [1] Sholanke Anthony Babatunde, Ajonye George Oche, Okpanachi Paul, "Fire Emergency Safety Preparedness in the College of Leadership Development Studies Building in Covenant University, Ota, Nigeria," Civil Engineering and Architecture, Vol. 8, No. 6, pp. 1463 - 1480, 2020. DOI: 10.13189/cea.2020.080628.
\end{abstract}

(b): Sholanke Anthony Babatunde, Ajonye George Oche, Okpanachi Paul (2020). Fire Emergency Safety Preparedness in the College of Leadership Development Studies Building in Covenant University, Ota, Nigeria. Civil Engineering and Architecture, 8(6), 1463 - 1480. DOI: 10.13189/cea.2020.080628.

Copyright $\bigcirc 2020$ by authors, all rights reserved. Authors agree that this article remains permanently open access under the terms of the Creative Commons Attribution License 4.0 International License

\begin{abstract}
Fire outbreaks often occur with the exigency of appropriate response from building occupants in order to safely escape it. Fire safety in buildings is a major design consideration in architecture which helps everyone to escape by way of the most harmless and closest exit point. This research is a case study of the fire emergency safety preparedness in the College of Leadership Development Studies building in Covenant University, Ota in Nigeria, to establish how prepared the building and its users are towards combating a fire outbreak, with a view to identify areas for further improvements. The study adopted a pragmatic research approach that made use of both qualitative and quantitative research methods. The results revealed that the fire emergency safety preparedness of the college building is low. The active and passive fire emergency safety provisions of the building, exhibited various levels of inadequacies. A significant finding was that there was no provision of any full scale firefighting devices in the building. Also, while most of the respondents can easily locate the active emergency firefighting hand appliances situated in the building, majority of them cannot operate the devices. Fire drills were also found not to be a regular periodic exercise in the building. Some of the recommendations made are that: the building should be retrofitted with the various active and passive fire emergency safety measures found to be lacking; also workshops, seminars and fire drills should be conducted periodically in conformity with best practices.
\end{abstract}

Keywords Fire Emergency, Fire Safety, Academic Buildings, Covenant University and Nigeria

\section{Introduction}

Fire outbreak is a disaster that results from anthropogenic activities either actively or passively. Fire safety encompasses all the processes involved in ensuring that fire is prevented, detected and controlled. Fire safety measures are taken in order to guarantee the safety of persons and protect properties from fire wreckage. Fire emergency preparedness is a phase of fire disaster management which aims at reducing the risks associated with fire incidences [1]. It is a cyclic process that involves systematic planning, assimilation of skills and knowledge, exercises, evaluations and improvement of methods in order to guarantee the effectiveness of coordinating and enhancing a facility's responsiveness to fire occurrences [2].

The occurrence of fire outbreak is experienced in school buildings in several countries around the world, amounting to scores of lives and properties being lost [3]. In a study carried out by the Arson Control Forum in the United Kingdom (UK) in 2006, fire incidences have occurred in close to $50 \%$ of educational institutions that were severe enough to require the intervention of emergency rescue 
teams. It was reported in the United States of America (USA) by the Fire Administration that fire outbreaks have occurred in some colleges, but were non-fatal in nature, given that the dangers are quickly put out as a result of the adherence to regulations. Most American schools are equipped with fire retardants, undertake fire drills regularly and are given information on how to react during such emergencies [4].

However, in Africa, school buildings experience fire outbreaks more frequently than other similar buildings in other places in the world. For instance, an educational institution in Kenya known as Kyanguli School, experienced an intense fire where 58 persons died as fire gutted a building in the school at night in 2001 [5]. In Wa, Ghana, it was reported that most multitenant facilities for students within the area had hostels that were not fortified with adequate facilities such as fire protection measures [6]. This puts the health and safety of students in jeopardy. In Nigeria, fire outbreaks have erupted in various tertiary institutions with buildings in Nile University in Abuja, University of Nigeria in Nsukka, Enugu State and Redeemers University, Ede in Osun State being some of the most recent victims of this menacing disaster. Olufemi [7] reported that a combination of carelessness and lack of fire-fighting equipment saw these fires escalate quickly beyond manageable levels. These fire disaster cases are few examples of the degree to which school buildings are susceptible to fire outbreaks as a result of inadequate preparedness of the learning environments towards firefighting and protection measures. Regrettably, training is also seldom given to occupants or users of buildings or building managers on how to use extinguishers usually hung on walls. In most cases, building occupants also lack the training required for directly reacting to infernos [3].

Fire emergency safety preparedness in learning institutions is attained when there is sufficient understanding of fire safety and when equipment and policies are made available to serve as measures taken beforehand so that harm is prevented in such situations [2]. However, this is not usually the case as a number of learning environments have been found to unknowingly risk the lives of its users to fire hazards which usually have adverse consequences on their health and safety. Occupants in a workplace ought to be sufficiently trained on how to operate a fire extinguisher or when to abandon a fire and call for help, as this can make the difference between survival and death [8]. Usually, the onus is on both staff and students to be compliable with given safety regulations to protect their lives during fire emergencies [9]. For instance, an understanding of how to use fire extinguishers serves as the vanguard to any fire protection endeavor.

According to Burtles \& Noakes [10], measures taken for fire emergency preparedness should also include accessibility to the building by fire fighters. This would facilitate the operations of firefighting trucks in combating fire and rescuing victims affected. Buildings should be designed with functional fire exits that are visible and free from anything that interferes with possible evacuation of persons during emergencies [11]. A workplace should offer to its users a high level of assurance that their lives are not in jeopardy, as long as they remain the property. There is no doubt that adequate firefighting and protection measures are provided in learning environments, it will go a long way to minimize losses and damage that may occur in the event of a fire outbreaks. Prevention, they often say is better than cure. It is however not certain if most institutions of learning in Nigeria are adequately equipped and users well prepared, to tackle fire outbreaks, because there is a dearth of empirical studies in this regard. Such studies are necessary as they are most likely to reveal grey areas for possible improvements.

It was based on the aforementioned that this study was conducted to evaluate the fire emergency safety preparedness in an academic environment in Nigeria to ascertain the level of preparedness of the academic setting in combating a fire outbreak. The aim of the study was therefore to evaluate the fire emergency safety preparedness in the College of Leadership Development Studies (CLDS) building in Covenant University (CU), Ota in Nigeria, with a view to identify areas for further improvements. The building is used on a daily basis by a large population made up of faculty, staff, students and visitors, whose lives and properties will be exposed to danger or loss if fire safety measures are not adhered to.

Fire incidences in university buildings pose a serious threat to public health. Despite the fact that fire outbreaks are not always reported in Nigeria, the damage left behind is evident, taking a heavy toll on persons, schools involved and the nation at large. Some studies have shown that fire outbreaks pose a frequent threat to academic buildings in Africa [3, 5 \& 7]. The reoccurrence of this scenario makes it expedient to investigate the current situation in an academic environment in Nigeria. This study adopted a case study approach to investigate this issue to allow for a detailed assessment at close range. To achieve the aim of the research, the study was conducted to answer the following questions in relation to the CLDS building in CU:

- What are the passive and active fire emergency safety measures employed?

- How adequate are the fire emergency safety measures provided?

- How aware are users of basic fire emergency safety protocols?

- To what extent are users able to operate common fire emergency safety devices?

Covenant University has two main college buildings namely the CLDS and the College of Science and Technology (CST) building. The scope of the study was limited to the CLDS building. The CLDS building was preferable for the research for two reasons. Firstly, it is the oldest academic building on the university campus. Secondly, it is the only academic building in the university 
that houses two colleges in one building, making it the most populated college building in the university. Also, the scope of the study investigation was limited to the views of students. The opinion of students on their level of awareness of fire safety emergency protocols and their ability to operate basic firefighting appliances, are considered crucial in determining the preparedness of the building and its users towards combating a fire outbreak. This is because students constitute the largest population of users of academic building generally. The study was further restricted to collecting information from undergraduate students who form the bulk of the students that make use of the building on a regular basis.

The outcome of the study has implications for the formulation and implementation of standard fire safety policies in public environments, particularly academic settings. The study findings are useful resource materials for benchmarking the fire emergency safety preparedness level of the CLDS building with that of academic buildings in other climes in Nigeria and around the globe. Building professionals and building management representatives will find the paper valuable towards the planning, implementation and management of adequate and reliable firefighting and protection measures in buildings, in the development of the built environment. The study is also a valuable resource material for students, educators and researchers to use, as well as build upon. The primary field data used in the study were gathered between November 2019 and January 2020. The contents of the manuscript are grouped under the following subheadings: abstract, introduction, literature review, methodology, results and discussion, conclusion, acknowledgements and references.

\subsection{Literature Review}

This part of the study consists of information from previous literature related to fire emergency preparedness in buildings. The sources of literature reviewed include published and unpublished works.

Fire is the phenomenon of combustion caused by the oxidation of a fuel source at high temperature [12]. It is a chemical process that is accompanied with the release of energy and the production of heat and light. This can be illustrated using the fire triad which consists of oxygen, heat and fuel as shown in Figure 1. Fire cannot occur if any of these three components are absent.

Fire has been present throughout the development of mankind. The history of fire dates as far back as the first appearance of plants, which is known to produce oxygen fuel needed for combustion. Sources of ignition have been present from inception in the form of natural phenomena such as lighting, volcanic eruptions and sparks from rocks. Before the existence of plants, there was no enough oxygen in the air to support burning [13]. This changed about 500 million years ago, when the increase in photosynthetic organisms on the planet created more oxygen in the atmosphere [14]. New findings claim that man developed the skill to create and contain fire as early as 1.5 million years ago. This claim is supported by Wayman [14] who stated that hominids built fires over a million years ago. This was reported after archeological findings discovered carbon remains of bones and plants dated back to about one million years old. However, the research agreed with the statement of Odegard [15] who highlighted that it is not possible to ascertain the origin of fire. The challenges associated with fire in those days were how to preserve it from quenching and how to control it from expanding to other unwanted areas. As a solution, caves served as covers, protecting the fire from winds while someone was chosen to attend to the fire and keep it from spreading.

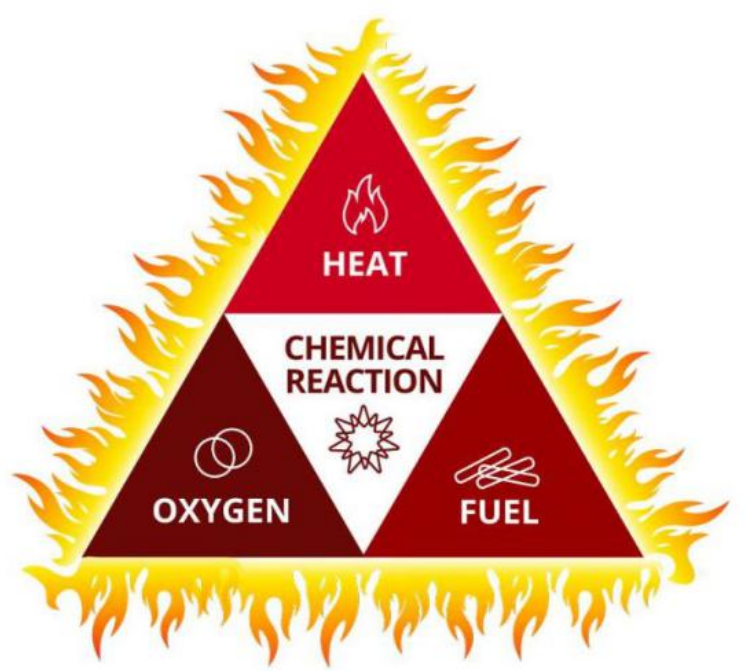

Source: Calams (2018).

Figure 1. The Fire Triad

According to Calams [12], the stages of fire are: ignition, growth, full development and burn out. The ignition stage starts with a combination of heat, oxygen and fuel, causing a little fire [16]. This can easily be put out using an extinguisher. At the growth stage, the intensity of the fire is increased when actors such as fire loads and increase in oxygen are used as additional fuel. The stage of full development of fire is when the growth stage steadily intensifies and fire reaches maximum temperature, leading to the burning of all combustible materials in the vicinity of the fire. This stage is regarded as the most hazardous for victims entrapped within building walls at the time of fire. The final stage known as the burn out stage, is when the intensity of the fire becomes reduced as a result of a steady decrease in the amount of oxygen and fuel. At this stage, one must ensure that extinguishers completely put out the fire to prevent new fires from starting as a result of reintroduction of oxygen into the space.

Fire is classified into different classes namely: A, B, C, $\mathrm{D}$ and $\mathrm{K}$ [17]. Class A is described as fire generated from fueling agents like paper, tree branches, chaff and refuse. Water can be used to put this class of fire out. Class B is fire 
that is generated from inflammable liquids such as petrol, oil and paint. To extinguish this class of fire, smothering to remove oxygen from the reaction can be used. Dry powder or foam can also be used to extinguish such fire. Class $\mathrm{C}$ are fire generated by wrong electrical connections. Burning can be stopped by cutting the power off or with the use of nonconductive extinguishers. Class D fire is caused when metals such as sodium, potassium, lithium are ignited. This class of fire can be put out using dry powder which acts as a heat absorber and smothering agent. Class $\mathrm{K}$ fire involves cooking fire and caused by combustion of liquids such as animal and vegetable fats. Wet chemical extinguishers are used in putting this class of fire out.

Fire is a state of burning caused by the quick oxidation of fuel [18]. It can be generated using several means and escalate quickly causing destruction of thing along its path. Fire in buildings is caused mostly when people are negligent and carry out activities such as wrongful disposal of lit cigarette sticks, careless wiring and overloading of power outlets and sockets. When electrical current fluctuates, it could lead to a fire incidence [19]. The habit of not turning off electrical switches and sockets is another cause. This is common when power in a building goes off and occupants forget to turn off electrical outlets [20]. As soon as electricity is restored with an increased voltage level, there is the possibility of it starting a fire caused by the electronics which are still plugged in and connected to the power source. Misuse of extensions beyond their load bearing capacity can also lead to fire incidences.

Other causes of fire in buildings include poor installation of electrical wires in close proximity to materials that are inflammable. Beaudrie [21] stated that kitchen fires can be caused when fire used for cooking comes in contact with other combustible materials. Also, when inflammable thrash is thrown away improperly and comes in contact with an ignition source, it can lead to fire. According to Adekunle et al. [22], fire is caused in buildings as a result of improper wiring and faulty installation of electrical equipment. Anaglatey [23] also observed that fire in institutional buildings result from poor electrical designs and illegal connections to other sources of electricity. Boateng [24] reported that severe winds and harmattan causing contact between high-tension wires, can also lead to fire outbreaks.

To therefore guide against the outbreak and spread of fire in buildings, it is important to adhere to fire protection measures. Fire safety preparedness is a key indicator that reflects the living standards and the extent to which a user's socio-economic and comfort needs have been met [6]. It is important to make sure that the measures provided are in good working condition. For instance, it is the escape routes that will get everyone in the workplace out of the building in the shortest possible time in case of a fire. Hence, they must always remain usable. It should be ensured that escape doors are working perfectly, that is, their automatic closers are functional, double doors align with each other when closed and smoke seals are not damaged. Escape route location signs should be clearly visible in workplaces to identify the direction of travel to exit the building and the sign on the fire exit doors indicating instructions for emergency door release, should be prominently displayed [17]. Fire risk assessment is a critical activity that helps in the protection of workers, as well as bringing institutions to adhere to the law of the land.

A well-trained firefighting team with well-defined responsibilities in case of fire should be established and on hearing the fire alarm sound, the team should assist fellow workers, visitors and customers by leading them through the fire exits. They should not allow people to come back to the building or even collect personal belongings unless clear escape is obvious. They should also make sure that everyone proceeds to the assembly point for a roll-call [25].

Fire prevention and protection activities can easily be implemented by establishment of a fire safety programme that includes inspection, fire drills, training, management procedures and communication. Fire drill is an important exercise for instilling skills on evacuation procedures and consequences of fire are completely avoidable if safety requirements are observed. Training must meet the goal of reducing the number of fires and thus reduce death and injury among workers and the financial loss on organisations [26].

In Nigeria, the National Building Code [27] sets minimum standards for the design and construction of buildings in the country to ensure quality, safety and proficiency in the building industry. Issues pertaining to fire protection and safety measures are largely addressed in Section 5 of the Code. It is specified in the Code that all roofs, floors and walls that are made of timber or have wooden members should have fire-retardant qualities or treated with fire-retardant materials, in order to limit combustion. For the construction of stairs, Section 5.3.5 stipulated that the material to be used should include reinforced concrete, steel and iron. The material finish on each tread and riser is specified as hard non-combustible materials such as brick or marble. Section 5.3.7 stipulated that every administrative building including offices and academic buildings with heights of $22.5 \mathrm{~m}$ above access roads for fire vehicles, should be equipped with sprinkler systems. The sprinkler systems should be automatic and provided on every floor with a shut-off valve and a water-flow device. It is mandated by the Code that all fixtures, both mechanical and electrical, should be checked often to ensure they are in perfect condition and in compliance with the fire safety code. In addition to the automatic sprinkler system, smoke detectors should also be installed in rooms designated for electrical equipment, mechanical equipment, power generators, communication equipment, elevator equipment and any other equipment room deemed fit. Wherever possible, the smoke detection system should be connected to a voice alarm system. This is to help control the spread of fire or smoke, so as to keep the building occupants safe and aware in case of a fire 
outbreak [27].

In providing for the alarm system, Section 5.3.7.4 of the National Building Code [27], stated that a combined system is required in order to ensure that the failure of one system would not impair the functionality of the other during fire emergencies. The combined system is made up of the voice alarm system, public address system and the fire department communications system. The three systems shall be provided in accordance to some specific requirements as follows: Firstly, the voice alarm system should be installed in such a way that whenever an automatic sprinkler or smoke detector goes off, that operation is followed by voice information that directs building occupants safely away from the fire. It shall be linked to a central control system that initiates either an automatic or general manual voice alarm message delivered audibly to its target area in the building. Secondly the public address system linked to the alarm system should be as audible as possible to all occupants of the building and should be operated from the central control station. It should be situated in areas such as lifts, lift lobbies, stairways, tenants' rooms, apartment spaces and hotel suites. Additionally, a fire department communication system should be installed and placed in such a way that it can be accessed from areas including lifts, lift lobbies and exit stairways [27].

To effectively respond to fire disasters, it is important to plan for coordinated measures that would curtail damage. In a study by Amaniampong, Ameyaw \& Akortsu [6], the authors stated that building developers and management officials should regularly carry out exercises that determine the quality of building components such as firefighting equipment and services that facilitate prompt escape and safety in case of a fire emergency. According to Kapoor [28], practical strategies which can be achieved with the available resources should be assessed, decided upon by the building management and implemented. In recent times it has become apparent that fire protection measures reach beyond using fire extinguishers and smoke detectors only. The two equipments make up a small portion of the protective measures a building should have at any time. Fire protection measures are usually classified into passive and active measures. According to Marco Protection Systems [29], fire protection services in buildings should not overlook other aspects of fire protection which is broadly divided into two types namely: Active Fire Protection (AFP) and Passive Fire Protection (PFP). Favorability of one type over the other must not be the case as both PFP and AFP should be complementary to each other to ensure adequate fire safety in buildings.

Active Fire Protection refers to the various elements of fire protection that need a form of action to be operational. The operating mechanism can be either manual, by the use of fire extinguishers for instance, or automatic as seen in sprinkler systems to douse fire [12]. Active performance of AFP measures is initiated by either a signal or alert.
However, it is the action that follows that will aid in containing, suppressing or extinguishing a fire. AFP consists of two systems namely: fire alarm systems and fire suppression systems. Fire alarm systems detect signals that set off a response which may either alert the fire department, activate sprinklers or close fire doors. Fire suppression systems such as clean agent systems, industrial dry chemicals and carbon dioxide extinguishing systems that are fully functional, can act as equipment to suppress a fire and put out flames before any harm is caused [29]. The requirement for fire buckets as an AFP measure is that they should be placed in visible and accessible positions such as corridors. A capacity of at least 10 liters is required for every fire bucket. It should be round-shaped, filled with dry sand and made with red painted metal to enhance its visibility [30].

Passive Fire Protection is usually disregarded, but is an essential part of fire protection in building. Unlike AFP, it requires no action to work and is made up of a group of building components that compartmentalise it, so as to contain the spread of fire. Structural building components such as fire-resistant walls and floors, dampers and fire doors are examples of PFP. Dampers help to prevent fire or smoke from spreading in a building through its ducts. Fire doors help in the compartmentalisation of fire, because they are made of fireproof materials. These doors limit possible loss or harm by removing fuel that could increase the extent of a fire to other areas of a building [17]. If this mechanism is effective, it reduces the risk of spread, which leads to protection against loss of properties and injury to persons. Although both the AFP and PFP fire protection measures function differently, they are both as evenly important. They should work simultaneously by prompting individuals within a building about a fire outbreak and help to contain the fire, so that people will respond by evacuating the building and/or suppressing the fire [29].

Passive Fire Protection also include functional and structural considerations such as exits, escape routes and fire resistance rating of wall/floor materials. For exits, any place where people live or work should have a primary exit and an emergency exit. Oke et al. [31] noted that the first requirement for fire safety in any building is the provision of adequate number of exit points in a building. It is expected that for small spaces, however, only a primary exit is required. Both exits should be free from obstructions or obstacles. The exits should guide people to an open deck in a direct manner. Exit doors should be operable from both sides with the capability of remaining opened and be situated in such a way that if a fire outbreak occurs within or around the building, it would not hinder the use of both exits at the same time [32]. All exits should open outwardly. The signage indicating both exits should be made of a photo luminescent sign comprising of a green pictogram and white symbol that has been approved by a product certification body [33].

Secondly, escape routes such as lobbies and stairways 
should be designed such that they provide a means of escape that leads to a muster point. However, if a ladder or stair is required to provide egress from the building, its exits should be fitted with a permanent ladder or stairway. More so, the stairway must be built with handrails on both sides, if its height is above a meter. Adler [34] noted that the staircase width for escape routes should be at least $760 \mathrm{~mm}$. However, according to Sholanke [35] \& Sholanke et al. [36], minimum effective staircase width in public spaces should be $1200 \mathrm{~mm}$ to allow at least two persons pass side by side.

Thirdly, fire resistance rating of building materials is also an important aspect of PFP. Fire resistance is the quality of a structural component to limit the degree by which excess heat passes when in use [37]. During the fire resistance period, the structural component should be able to maintain its capability to keep a fire from escalating while continuing to perform the required structural function. The National Institute of Standards and Technology [38] described fire resistance rating of a material as a period of time, not more than four hours, a structural element is able to provide fire resistance. Materials are rated based on hourly or half-hourly increments of fire resistance. Fire resistance rating was before now determined by testing a sample of the wall and how it performs when exposed to a regulated fire for a duration of time, proceeded by dousing it with water from a hose. However, in recent times, due to the cost of assembling and constructing the required testing specimen and equipment for fire testing, the Masonry Society and the American Concrete Institute devised a method for calculating fire resistance. This method specified certain criteria that are needed, to know the fire resistance rating of various materials. Concrete masonry units (CMU) are largely used as fire walls because of the non-combustible nature of concrete. The National Institute of Standards and Technology [38] stipulated that for a masonry construction to be fire resistant, it should resist absolute combustion of its contents without giving way. In addition, a CMU made of limestone with total thickness of 4 inches (excluding the hollow core area) have a fire rating of 2-hours and a wall made of this is safer and experiences lesser property damage than a wood-frame wall with the same fire rating.

Fire doors also form a barrier to stop the spread of fire. They compartmentalise a fire, provide a means of escape and protect an escape route though the building. Fire risk assessment should be done to identify fire resistance of a fire door. The fire rating of fire doors is measured using a prefix of letters 'FD' [39]. For instance, FD30 stands for a 30-minute fire door that offers at least 30-minute protection against fires. Other classes include FD60, FD90 and FD120. For high risk buildings such as factories, metal fire doors should be used as they can obtain a rating of up to 4 hours. However, a 90-minute rating can be obtained by wooden fire doors. Building regulation requires that for any building which has up to three or more storeys. But it is advisable to use a fire door wherever a fire might start. Fire doors usually have more thickness (at least $45 \mathrm{~mm}$ ) than ordinary doors $(35 \mathrm{~mm})$. They can be made of a combination of materials such as timber, glass, gypsum, aluminum and vermiculite boards [39]. To check the quality of already constructed fire, it should weigh heavier than a normal door. Secondly, the frame should have a certification mark or label indicting the manufacturer and the fire rating. In addition, the door should have a $4 \mathrm{~mm}$ gap on the top and side of the door when it is closed with no gap at the bottom. It should close firmly onto the latch without sticking on the floor.

Fire signage is another important passive fire emergency measure. According to Dalto [40], there are some few specific regulations about fire signage. Occupants should be able to identify where they are mounted. This can be ensured by mounting them at points where they are seen without any obstruction such as opened doors. Another main regulation for a safety sign is that it must include a pictogram that clearly identifies its meaning. Written texts may be used to enhance understanding, but it is prohibited to use text-only signage [17].

Hopper [41] explained that in the aspect of site planning, the use of space around the building should be such that it can allow for a fire vehicle to intervene by being able to move around the building if need be, during a fire outbreak. Spaces around the building must make it practical for rescue and external firefighting operations to be mounted. This is achieved by providing an access way such that the site is accessible to firefighting appliances. Access ways should be designed with a width of at least $4 \mathrm{~m}$ through its full distance. The material should be made of either perforated slabs, metallic materials or paved to bear the 30 tonnes stationary load of a fire vehicle. The access way should enable fire vehicles to enter, manoeuvre and extend equipment such as ladders and pumps, turntables and hydraulic platforms. The outer turning radius of the access road for the fire vehicle should be at least $7 \mathrm{~m}$ and comply with the other requirements shown in Figure. 2. 


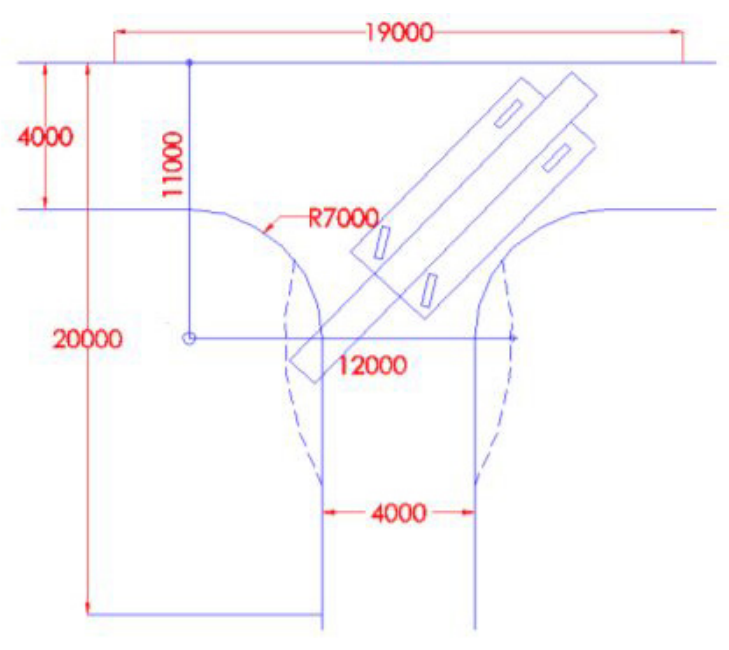

Source: scdf.gov.sg

Figure 2. Turning Radius for a Fire Vehicle

The requirements in Figure 3 are for buildings with a minimum habitable height of $10 \mathrm{~m}$ and a maximum horizontal height of $10 \mathrm{~m}$ between the fire vehicle and the building as shown in Figure 3.

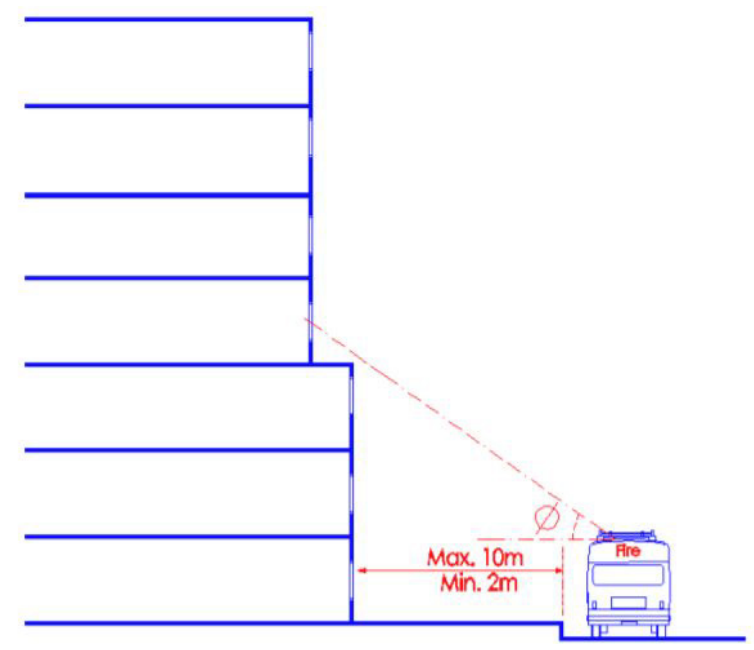

Source: scdf.gov.sg

Figure 3. Required Distance between a Fire Vehicle and a Building

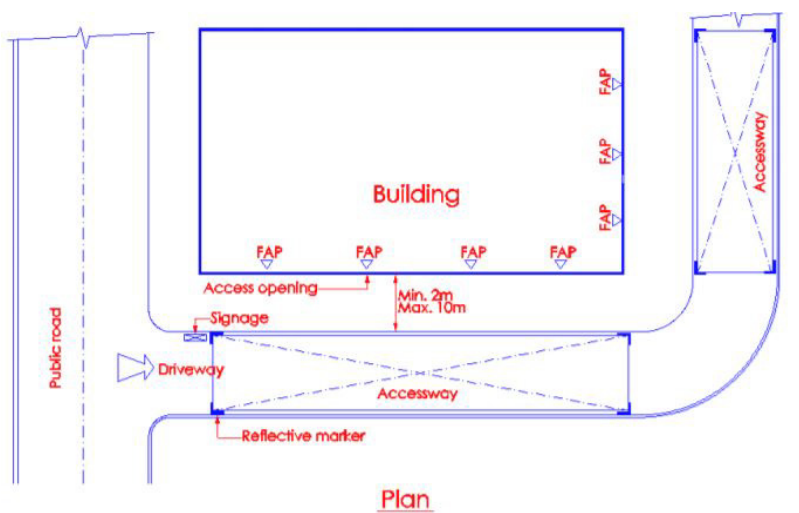

Source: scdf.gov.sg

Figure 4. Location of the Fire-Vehicle-Access Signage
A signage displaying "Fire Vehicle Access - Keep Clear" ought to be placed at the entrance of the fire vehicle access way with a size of at least $50 \mathrm{~mm}$ for each word as indicated on Figure 4.

Another consideration in site planning as explained by Hopper [41] is that the drive-way layout should be such that there is a cul-de-sac or t-turn on one end of an access way for fire vehicles. The fire hazard level of a building determines both the distance between fire extinguishers and the type of extinguisher to be placed within a building. According to Unifour Fire \& Safety [42], fire hazard levels are categorised into light, ordinary and extra fire hazard. Schools, churches, assembly halls and other buildings with minimal fire risks are categorised under the light fire hazard level. The type of extinguisher required for this is a $2 \mathrm{~A}$ extinguisher with a travel distance of not more than 23 meters from one extinguisher to the other or one should be placed within 3000 square feet [42]. Mounting fire extinguishers require that they are placed on wall brackets or wall cabinets with the handle for carrying them placed between $1 \mathrm{~m}$ to $1.2 \mathrm{~m}$ above the floor level [40]. However, bigger extinguishers should be placed at a maximum height of 1 meter above the floor level.

In recent time, digital advancement and technology has brought about innovations towards improving fire safety preparedness of buildings. Presently, the use of voice evacuation systems in case of fire incidences now exists. The system is useful for directing users on how to evacuate a building in the advent of a fire outbreak.

\section{Materials and Methods}

This research was conducted to determine the level of fire preparedness in the CLDS building in Covenant University, Ota in Nigeria, towards identifying areas for possible improvements. The study is therefore naturally a case study research. To achieve the aim, four objectives were set as earlier stated in the introduction. The most suitable research approach to addressing each objective was adopted and used. This necessitated the use of both qualitative and quantitative research methods to carry out the study. For this reason, the study is pragmatic in nature. Primary qualitative field data were gathered with an observation guide developed for the research, as well as pictures taken with a digital camera. Qualitative data were analysed by content analysis. The key components of the observation guide were sieved from relevant sections of the documents reviewed while gathering materials for the literature review section of the study.

A structured questionnaire developed for the study was employed to collect primary quantitative data from respondents who were mainly students whose departments are situated in the college building. The questionnaire was adopted to elicit data from the participants due to the large number of students involved. It was observed that approximately a little over 500 students make use of the 
building daily, on working days. To arrive at the sample size, the study adopted the recommendation of Nwana (1981) cited by Sholanke [35] and Oluwunmi [43], who advanced that a minimum sample of $40 \%$ is suitable for any study. A total of 250 questionnaires were therefore distributed within the college building on a particular working day which represents about $50 \%$ of the number of students who use the building daily. The questionnaire was administered during students' free periods to allow them enough time to provide answers to the questions. The students who participated in the study were undergraduate students who were randomly selected to avoid any form of bias. Before participating in the study, the students were informed of the reason for the research which is strictly for academic purpose. Before answering the questions, the respondents were clearly informed that they are free to decide if they wish to partake in the study or not and assured that the information they provide will be treated anonymously and used strictly for academic purpose. Therefore, every student who participated in the research did so out of their free will without any form of undue pressure or intimidation.

The questionnaire administered was developed with three sections. The first section was used to gather information on relevant personal characteristics of the students, as well as provide them with enough background information on the research to make them decide on whether they wish to participate in the study or not, as just explained. The second section was employed to collect information on the level of awareness of the participants on the fire safety measures employed in the college building. Whereas, the third section was used to gather data on the extent to which the respondents are able to effectively operate basic firefighting devices provided in the college building, as well as their awareness level on basic fire emergency protocols. Statistical Package for Social Sciences (SPSS) was used to analyse the quantitative data. The results of the study were presented by descriptive approach with the aid of tables and pictures.

\subsection{Results}

The CLDS building was commissioned at the inception of the university in 2002. The building comprises of four floors. The number of colleges in the building is two, namely: College of Business Studies (CBS) and College of Human Development (CHD). Both colleges constitute the College of Leadership Development Studies (CLDS). Out of the 250 questionnaires administered within the building as earlier mentioned, 224 were returned, found to be valid and used. The questionnaire retrieval rate is $89.60 \%$, which is considered a reasonable response rate.

\subsubsection{Personal Characteristics of Respondents}

Table 4.1 shows the personal characteristics of the participants who were randomly selected.

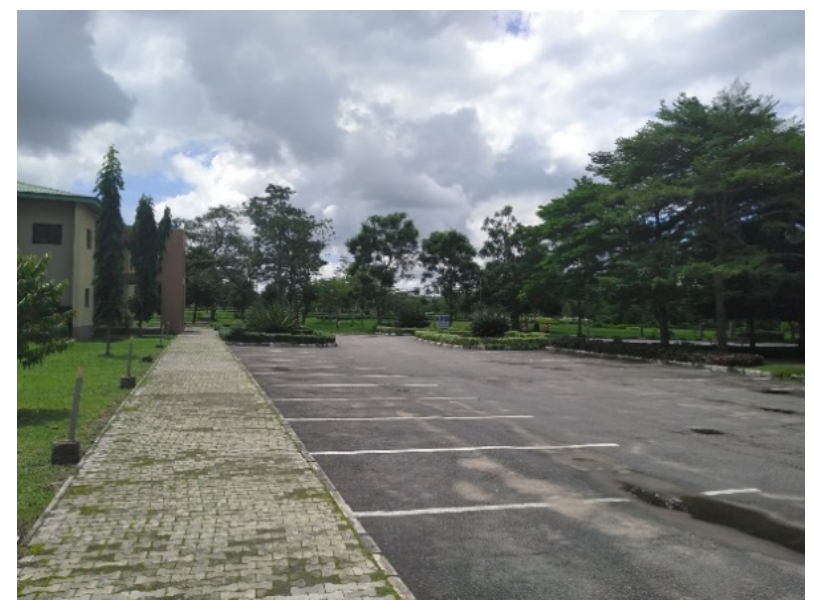

Figure 11. Side view of the Building with Adequate Vehicular Manoeuvring

Table 1. Personal Characteristics of Respondents

\begin{tabular}{|c|c|c|c|c|}
\hline $\mathrm{SN}$ & Variable & Group & Frequency & Percentage \\
\hline \multirow{3}{*}{1} & \multirow{3}{*}{ Gender } & Male & 107 & 47.80 \\
\hline & & Female & 117 & 52.20 \\
\hline & & Total & 224 & 100.00 \\
\hline \multirow{4}{*}{2} & \multirow{4}{*}{ Age } & $16-20$ years & 176 & 78.60 \\
\hline & & $21-25$ years & 43 & 19.20 \\
\hline & & Above 25 years & 5 & 2.20 \\
\hline & & Total & 224 & 100.00 \\
\hline \multirow{5}{*}{3} & \multirow{5}{*}{$\begin{array}{l}\text { Level of } \\
\text { Study }\end{array}$} & 100 & 53 & 23.70 \\
\hline & & 200 & 119 & 53.00 \\
\hline & & 300 & 49 & 21.90 \\
\hline & & 400 & 3 & 1.30 \\
\hline & & Total & 224 & 100.00 \\
\hline \multirow{7}{*}{4} & \multirow{7}{*}{ Departments } & Languages and & & \\
\hline & & General Studies & 24 & 10.70 \\
\hline & & $\begin{array}{c}\text { Psychology } \\
\text { Political }\end{array}$ & 86 & 38.40 \\
\hline & & Science \& & & \\
\hline & & International & 114 & 50.90 \\
\hline & & Relations & 224 & 100.00 \\
\hline & & Total & & \\
\hline \multirow{6}{*}{5} & \multirow{6}{*}{$\begin{array}{l}\text { Length of } \\
\text { use in the } \\
\text { Building }\end{array}$} & Less than one & & \\
\hline & & year & 45 & 20.10 \\
\hline & & $1-2$ years & 111 & 49.60 \\
\hline & & 3 years and & 68 & 30.30 \\
\hline & & above & 224 & 100.00 \\
\hline & & Total & & \\
\hline
\end{tabular}

The data in Table 1 shows that $47.8 \%$ of the respondents are males while $52.2 \%$ are females. This means that the result presented is devoid of gender bias, because there is almost an equal representation of both males \& females in the study. On age groupings, the majority $(78.6 \%)$ of the respondents are between the age range of $16-20$ years, some (19.2\%) are between $21-25$ years, while few $(2.2 \%)$ are above 25 years of age. The age distribution shows that majority of the respondents are between the age range of 16 -20 years. This is not surprising as a significant number of universities in Nigeria, particularly private universities admit students from the age of 15 years. On level of study of the participants, the table revealed that some $(23.7 \%)$ of the respondents are in their first year, whereas most of them 
$(53.0 \%)$ are in their second year. Some $(21.9 \%)$ are in their third year, while few (1.3\%) are final year students. This result indicates that majority of the respondents are in their second year and above. Hence, the reliability of the views of majority of the respondents is considered reasonable. This implies that most of the respondents have spent at least more than a year as students, which is considered enough length of time for such respondents to be able to provide reliable informed judgment on what obtains in the building with regards to fire safety and protection measures. On the department of the respondents, the table shows that few of them $(10.7 \%)$ are students studying Languages and General Studies, some (38.4\%) Psychology, while most of them $(50.9 \%)$ are students of Political Science \& International Relations. The result indicates that majority of the respondents are from the Department of Political Science and International Relations, which implies that the opinion of the students collected is dominated by that of those from this department. For the duration of stay in the building, the table indicated that few (20.1\%) of the respondents have spent less than a year in the university. Some $(30.3 \%)$ have spent 3 years and above, whereas most of them (49.6\%) have spent between $1-2$ years and. This implies that the complete picture of the opinion of the respondents relied upon in this study is reliable, because most of the participants have spent over a year using the college building on a regular basis when the school is in session. Hence, such user category should be able to provide information that is reliable towards achieving the purpose of the research.

Table tools in Microsoft Word are recommended for inserting a table. It's necessary to avoid tables created with the tab key.

\subsubsection{Fire Emergency Safety Measures Employed}

The analysis of the findings on the fire emergency safety measures employed in the college building indicated that both active and passive measures were provided for. The result of the investigation is displayed in Table 2 in relation to minimum standard required in a public building of this nature.

The result displayed in Table 2 shows that majority of the expected active and passive fire emergency safety measures in a public building of this nature were not provided in the college building. Out of all the possible active firefighting and protection emergency measures envisaged, only two (fire extinguishers and fire buckets) were provided for as shown in Figure 5 and Figure 6.

Table 2. Passive and Active Fire Emergency Safety Measures Employed

\begin{tabular}{|c|c|c|c|c|}
\hline \multirow{2}{*}{ SN } & \multirow{2}{*}{ Variable } & \multirow{2}{*}{ Nature of Variable } & \multicolumn{2}{|c|}{ Remarks } \\
\hline & & & Available & Not Available \\
\hline \multicolumn{5}{|c|}{ (A) Active Firefighting Emergency Measures } \\
\hline 1 & Fire extinguishers & Availability on each floor & $\checkmark$ & \\
\hline 2 & Fire buckets & Availability on each floor & $\checkmark$ & \\
\hline 3 & Hose reels & Availability in the building & & $\checkmark$ \\
\hline 4 & Fire blankets & Availability on each floor & & $\checkmark$ \\
\hline 5 & Wet risers & Availability in the building & & $\checkmark$ \\
\hline 6 & Dry risers & Availability in the building & & $\checkmark$ \\
\hline 7 & Fire alarms & Availability on each floor & & $\checkmark$ \\
\hline 8 & Smoke detectors & Availability in the building & & $\checkmark$ \\
\hline 9 & Drenchers & Availability in the building & & $\checkmark$ \\
\hline 10 & Sprinklers & Availability in the building & & $\checkmark$ \\
\hline \multicolumn{5}{|c|}{ (B) Passive Fire Emergency Protection Measures } \\
\hline \multirow{2}{*}{1} & \multirow{2}{*}{$\begin{array}{l}\text { Structural building } \\
\text { components }\end{array}$} & Availability of fire-resistant walls & $\checkmark$ & \\
\hline & & Availability of fire-resistant floors & $\checkmark$ & \\
\hline 2 & Duct works & Availability in the building & & $\checkmark$ \\
\hline 3 & Fire doors & Availability in the building & & $\checkmark$ \\
\hline 4 & Fire exits & Availability in the building & $\checkmark$ & \\
\hline 5 & Escape routes & Availability on each floor & $\checkmark$ & \\
\hline 6 & Fire signage & Availability in the building & & $\checkmark$ \\
\hline 7 & Muster point & Availability in the building & & $\checkmark$ \\
\hline 8 & Site planning & $\begin{array}{l}\text { Availability of adequate space around the building for } \\
\text { manoeuvring of fire vehicles }\end{array}$ & $\checkmark$ & \\
\hline
\end{tabular}




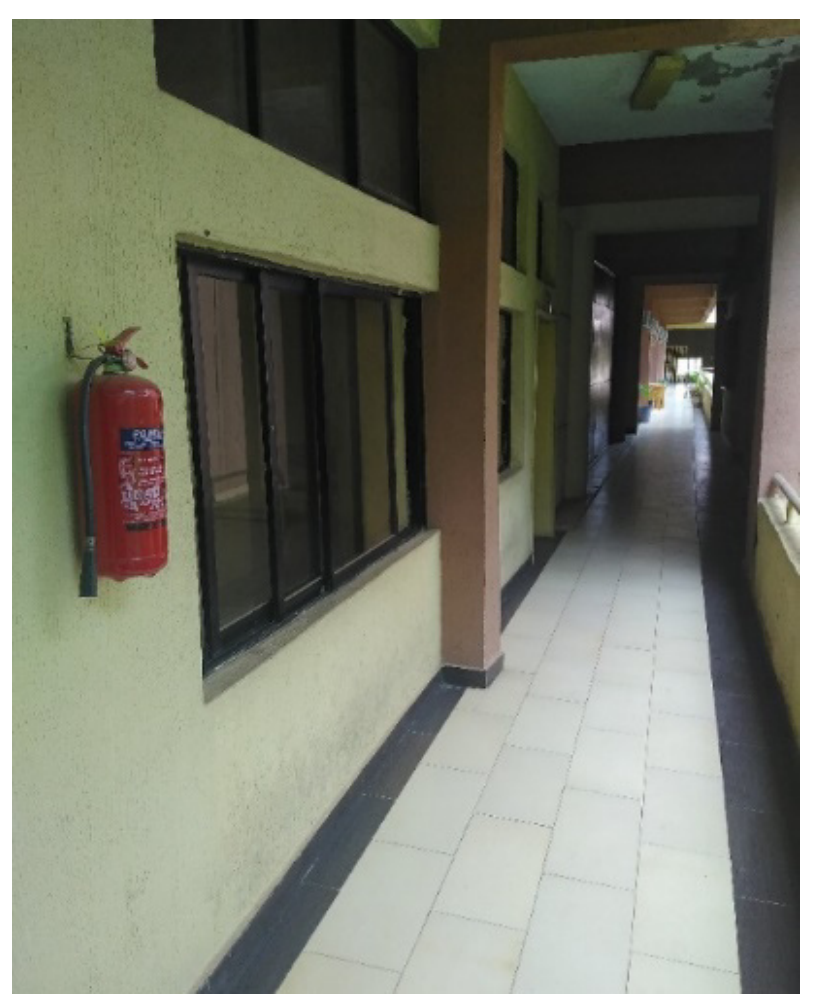

Figure 5. Fire Extinguisher hung along a corridor

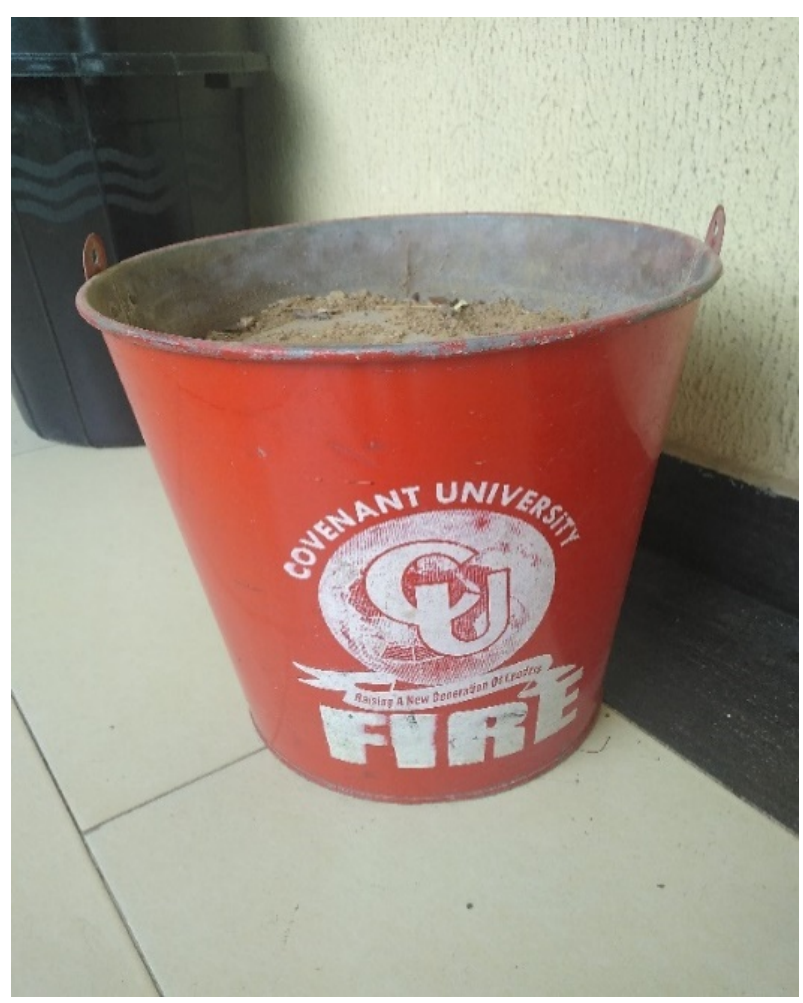

Figure 6. Fire bucket positioned along a corridor

Measures such as automatic fire detection devices, fire alarm systems and fire blankets were not provided for in the building. Also, conspicuously missing in the structure are full scale fire emergency safety systems such as hose reels, wet or dry risers, drenchers and sprinklers. With regards to passive fire emergency safety measures, several provisions were identified. They include: the use of fire walls and floors, fire exists, sizeable and unobstructed escape routes within the building and adequate space around the building for manoeuvring of fire vehicles. 
Nevertheless, measures such as dampers, fire doors, fire signage and muster points were found not to be provided for. The fire walls are sandcrete block walls of between $150 \mathrm{~mm}$ and $225 \mathrm{~mm}$ thick, rendered on both sides. The fire floors are reinforced concrete slabs finished with tiles, while their underneath in upper floors are screeded with sand/cement plaster. Figure 7 shows an example of a non-fire resistant door used in the building, while Figure 8 are examples of fire resistant walls and suspended floor, viewed from a corridor in the building.

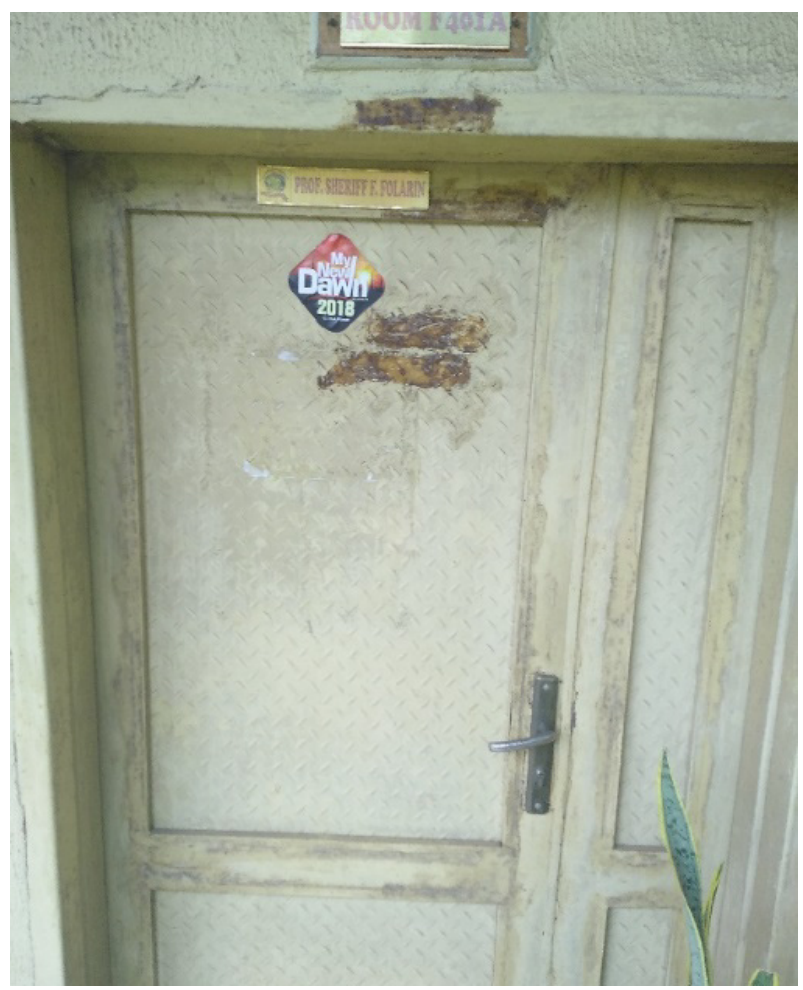

Figure 7. Non-Fire Resistant Door

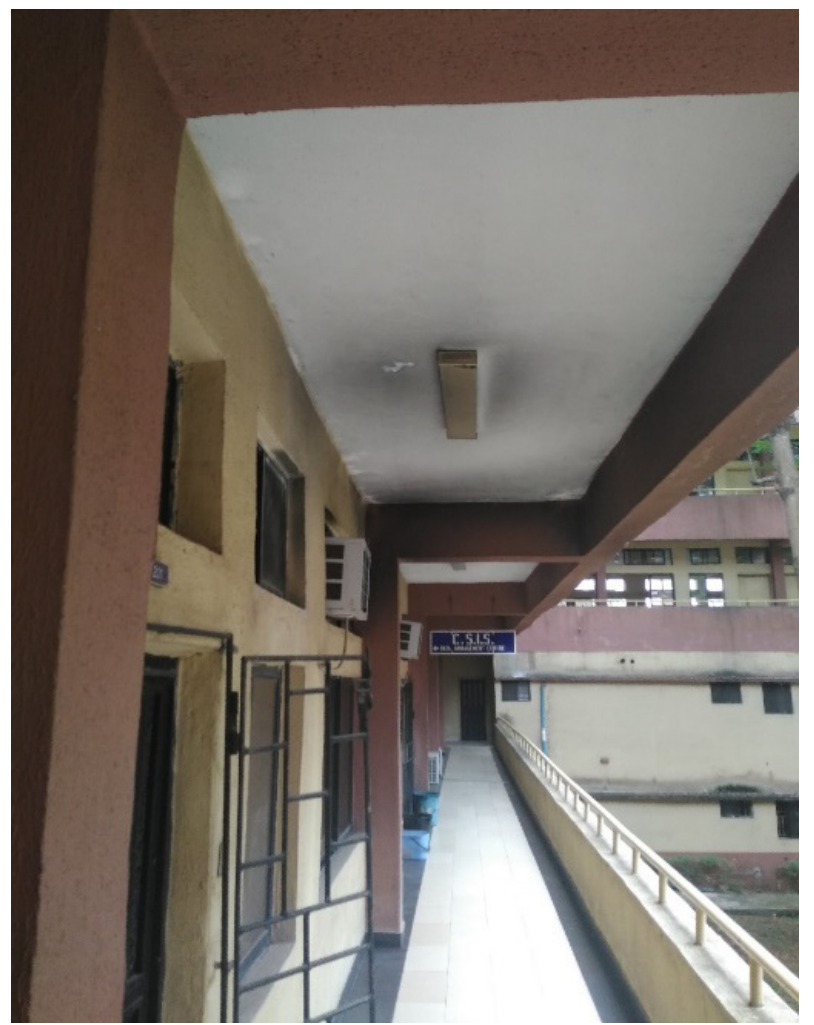

Figure 8. Fire Resistant Walls and Floors 


\subsubsection{Adequacy of the Fire Emergency Safety Measures Provided}

The result just presented on the fire emergency safety measures provided in the CLDS building shows that majority of the safety provisions expected in a public building of this nature were not provided for in the building. The most affected are the active firefighting and protection emergency provisions, where only two out of the ten expected measures were found in the building, as shown in Table 2. The provisions are adjudged highly inadequate as majority of the expected safety measures such as, automatic fire detection devices, fire alarm systems, fire blankets and full scale firefighting and protection measures such as hose reels, wet or dry risers, drenchers and sprinklers, were not provided for. Out of the only two active firefighting appliances provided, none is a full scale firefighting measure. This implies that in a case where a fire outbreak cannot be put off by the hand appliances, the building does not have any in-built full scale firefighting emergency system that can be employed to combat the fire in conformity with best practices. The implication of this result is that while small scale fires may easily be put off before causing a major damage, large scale fires are most likely to cause significant damage before they can be brought under control.

With regards to the passive fire emergency safety measures provided, the provisions made are also inadequate, though slightly. This is as a result of some measures such as dampers, fire doors, fire signage and muster points not provided for. These provisions are common and necessary requirements of public buildings towards enhancing the safety of users in the event of a fire outbreak. Only four of a possible nine passive fire safety provisions were available in the building, as shown in Table 2. It is therefore safe to conclude that whereas the passive fire emergency safety measures are slightly inadequate, the active firefighting provisions are highly inadequate. But on a general note, the fire emergency safety provisions of the college building are not justifiably sufficient, hence adjudged not reasonably adequate.

However, with regards to specifics, some of the fire emergency safety measures available in the building were discovered to be reasonably provided. For instance, fire buckets filled with sharp sand were generally positioned along corridors at reasonable distance to one another and painted red, in conformity with standard practice, as shown in Figure 6. The sand in the fire buckets are readily accessible for use if need be, by anyone walking along the corridors. Likewise, fire extinguishers are hung along the corridors where they can easily be reached by users of the building. They are spaced at between $15 \mathrm{~m}$ to $20 \mathrm{~m}$ interval at reachable heights as shown in Figure 5. However, the reliability of some of the fire extinguisher is doubtful, as the date when they were last serviced to be sure they are functional and reliable when needed, was over a year ago from when the field data for this research was collected. The fire resistant walls provided are also adjudged adequate and reliable as they fall within the Concrete Masonry Units (CMU) of $100 \mathrm{~mm}$ thickness (excluding hollow cores) made of siliceous aggregates which offer a 2-hour fire resistance rating, based on the guidelines provided by National Concrete Masonry Association [44]. Likewise, the suspended floor slabs used in the building generally, are reinforced concrete floor slabs which naturally has a high fire resistance quality.

For fire exits, it is standard practice that buildings such as the CLDS building should have a primary exit and an emergency exit. Apart from the main entrance which serves as the primary exit to the building, some other exist points located at strategic positions within the building, exist in line with general fire safety guidelines. The exits are provided to assist users in evacuating the building at different locations on the ground floor. The exit doors are operable from both sides with the capability of remaining opened and situated such that they can all be used at the same time. The doors are large enough to enable more than one person pass at a time, thereby capable of allowing for mass movement in case of emergency. The fire safety requirements of the exit doors are adjudged reasonable and reliable as their provisions conform with standard requirements found in previous literature. According to Oke et al. [31], the first requirement for fire safety in any building is the provision of adequate number of exit points in a building.

Escape routes, general movement corridors and staircases are also generally considered adequate and reliable as their provisions conform with standard fire emergency safety requirements. Widths of general movement spaces are largely $1.5 \mathrm{~m}$ and above. Staircases have an effective minimum width of $1.8 \mathrm{~m}$ and provided with handrails for safety and support purposes as shown in Figure 9.

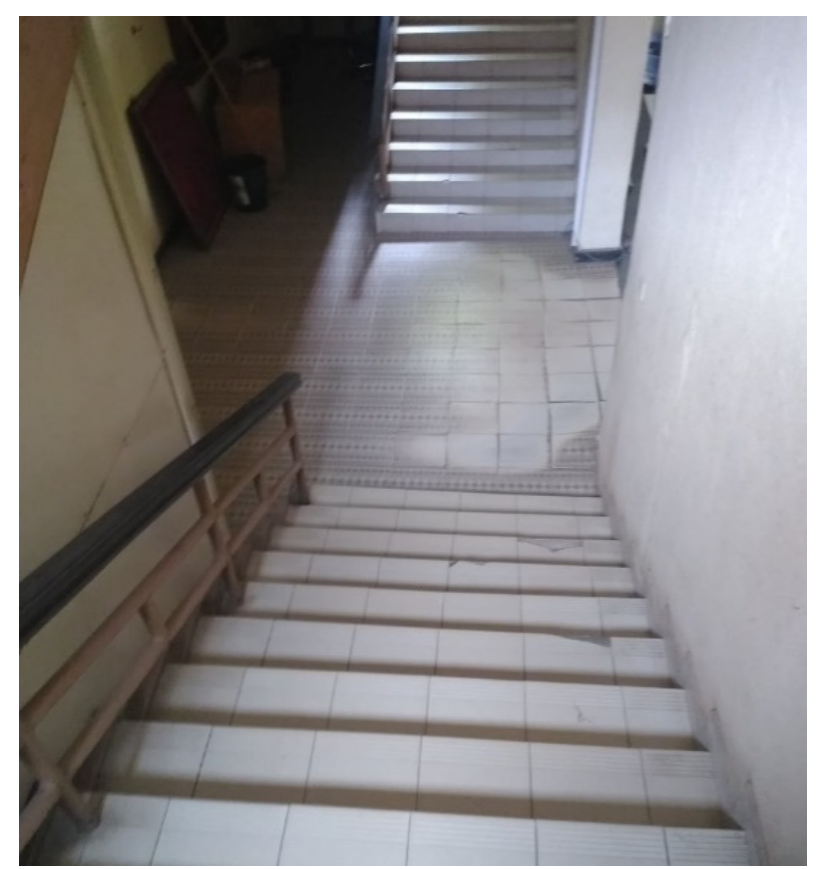

Figure 9. Staircase Flight Lobby 
The escape routes sizes are adequate for mass movement in case of emergency. Their floor surfaces are finished with vitrified tiles. The floors are hard, non-slippery and considered safe to use in line with universal design requirements highlighted by Sholanke et al. [36]. Though fire signage which helps users to find their way towards exits in case of emergency were not provided in the building, nevertheless, the movement and escape routes are generally free from obstacles that can hinder mass movement. Based on the general findings on the escape routes, they are adjudged reliable. According to Kironji [45], the primary function of escape routes is to guide people to a point of relative safety within the shortest possible time, which the escape routes conform with.

Site planning for fire protection requires that fire apparatus such as trucks, ladders, pumps and tankers have unobstructed access to reach a building. The building has adequate space around it to accommodate mass pedestrian movements and fire apparatus, including fire vehicles in case of a fire emergency, as shown in Figure 10 and Figure 11.

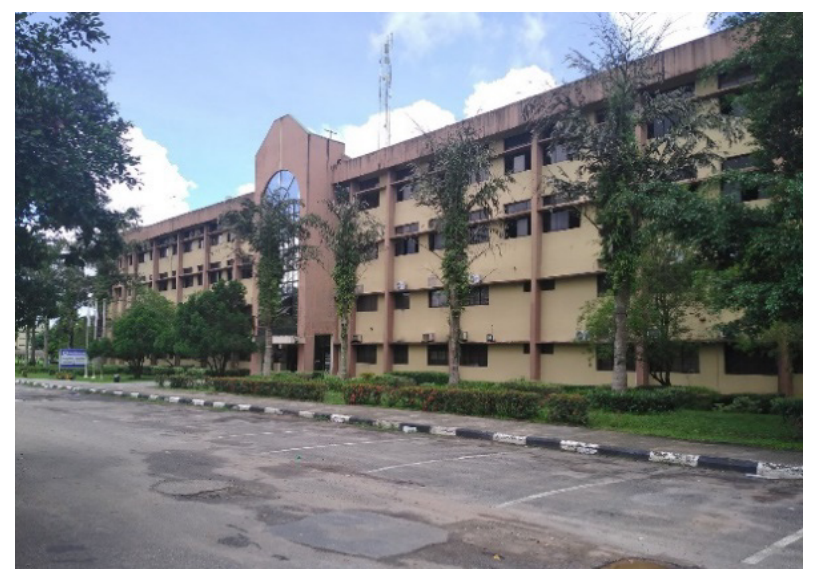

Figure 10. Front view of the Building with Adequate Vehicular Manoeuvring Space

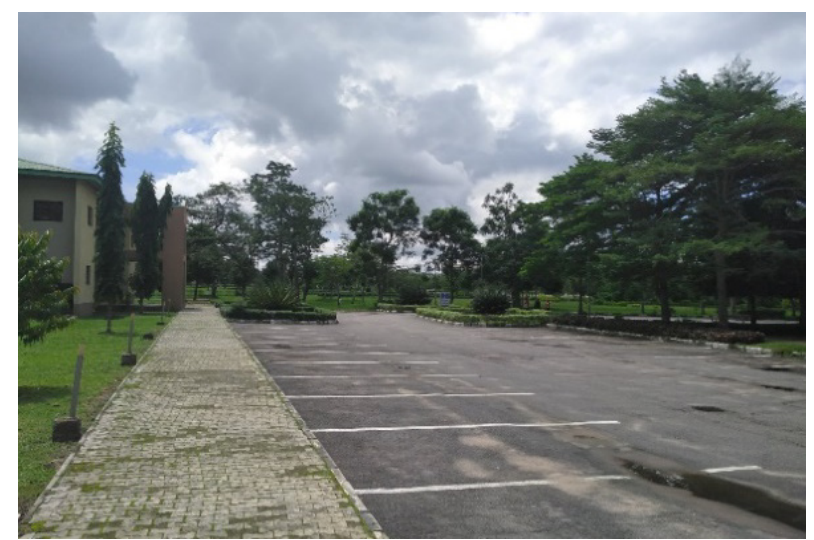

Figure 11. Side view of the Building with Adequate Vehicular Manoeuvring

The pedestrian walkways along the car parks are large enough to allow for mass movement, while adequate turning space is available within the car park areas for fire trucks to manoeuvre and turn around, as shown in Figures 10 and 11. Hopper [40] reported that drive-way layout in such a building should have a cul-de-sac or t-turn on one end of an access way for fire vehicles. From the findings on the planning of the site, the site planning conforms with fire safety standards and adjudged a reliable passive fire emergency safety measure for the building. However, it was observed that no specific point was designated as a muster point for the building in line with standard practice. Such points are usually located at a safe distance outside public buildings where people can gather for a roll-call to ascertain that everyone in the building is safely out of the building, in the event of an emergency such as a fire outbreak.

Judging by the overall picture of the result, the active and passive fire emergency safety provisions employed in the CLDS building conform with standard practice as shown in previous literature, but not satisfactorily sufficient based on the various inadequacies highlighted.

\subsubsection{Users Level of Awareness of Basic Fire Emergency Safety Protocols}

\section{A. Users Awareness on What to do in Case of a Fire Outbreak}

The participants' responses on their level of awareness of fire emergency safety measures employed in the college building are grouped under three possible answers of "Not Aware", "Not Certain" and "Aware". The result is presented in Table 3.

Table 3. Users Awareness on What to do in Case of a Fire Outbreak

\begin{tabular}{|c|c|c|c|c|}
\hline $\mathbf{S N}$ & Variable & Group & Frequency & $\begin{array}{c}\text { Percentage } \\
(\%)\end{array}$ \\
\hline \multirow{4}{*}{1} & \multirow{4}{*}{$\begin{array}{l}\text { Awareness of } \\
\text { fire emergency } \\
\text { number to call }\end{array}$} & $\begin{array}{c}\text { Not } \\
\text { Aware }\end{array}$ & 214 & 95.5 \\
\hline & & $\begin{array}{c}\text { Not } \\
\text { Certain }\end{array}$ & 10 & 4.5 \\
\hline & & Aware & 0 & 0 \\
\hline & & Total & 224 & 100 \\
\hline \multirow{4}{*}{2} & \multirow{4}{*}{$\begin{array}{l}\text { Awareness of } \\
\text { location of fire } \\
\text { exits }\end{array}$} & $\begin{array}{c}\text { Not } \\
\text { Aware }\end{array}$ & 134 & 59.8 \\
\hline & & $\begin{array}{c}\text { Not } \\
\text { Certain }\end{array}$ & 25 & 11.2 \\
\hline & & Aware & 65 & 29 \\
\hline & & Total & 224 & 100 \\
\hline \multirow{4}{*}{3} & \multirow{4}{*}{$\begin{array}{l}\text { Awareness of } \\
\text { location of fire } \\
\text { retardant devices }\end{array}$} & $\begin{array}{c}\text { Not } \\
\text { Aware }\end{array}$ & 53 & 23.7 \\
\hline & & $\begin{array}{c}\text { Not } \\
\text { Certain }\end{array}$ & 3 & 1.3 \\
\hline & & Aware & 168 & 75 \\
\hline & & Total & 224 & 100 \\
\hline \multirow{4}{*}{4} & \multirow{4}{*}{$\begin{array}{l}\text { Awareness of } \\
\text { how to operate } \\
\text { most fire } \\
\text { retardant devices }\end{array}$} & $\begin{array}{c}\text { Not } \\
\text { Aware }\end{array}$ & 168 & 75 \\
\hline & & $\begin{array}{c}\text { Not } \\
\text { Certain }\end{array}$ & 3 & 1.3 \\
\hline & & Aware & 53 & 23.7 \\
\hline & & Total & 224 & 100 \\
\hline
\end{tabular}


The result in Table 3 shows that most $(95.5 \%)$ of the respondents are not aware of any fire emergency number to call during a fire incidence. None was found to be aware, whereas just few $(4.5 \%)$ are not sure of their opinion. On users' awareness of the location of fire exits in the building, again majority (59.8\%) are not aware, while some (29\%) are aware. Just a few $(11.2 \%)$ are not certain if they are aware or not. This result indicates that in case of a fire incidence, most of the respondents will be unable to either call the appropriate emergency lines or find their way out of the building through designated fire exit doors without difficulty.

The data in Table 3 also indicate that some (23.7\%) of the respondents are not aware of the location of fire retardant systems in the college building, but majority $(75 \%)$ are aware. Those who are not certain of their opinion are few $(1.3 \%)$. However, while most of the respondents are aware of the location of fire retardants devices in the building, majority $(75 \%)$ are not aware of how to operate most of the devices. Only some (23.7\%) are of the opinion they can operate majority of the devices, while just few $(1.3 \%)$ are uncertain of their view. This implies that in the advent of a fire, while most of the users will be able to locate fire retardant devices incorporated in the building, majority will not be able to operate most of the appliances, which in a way defeats the essence of providing such fire retardants in the first place.

\section{B. Users' Ability to Respond Appropriately in Case of a Fire Outbreak}

To evaluate users' ability to respond appropriately in the event of a fire outbreak in the building, the respondents were asked to indicate if they are aware of some basic fire safety precautionary tips expected in such a building. Again, the participants were provided with three possible answers of "Not Aware", "Not Certain" and "Aware" to choose from. The findings are presented in Table 4.

Table 4. Users Ability to Respond Appropriately in Case of a Fire Outbreak

\begin{tabular}{|c|c|c|c|c|}
\hline $\mathrm{SN}$ & Variable & Group & Frequency & $\begin{array}{c}\text { Percentage } \\
(\%)\end{array}$ \\
\hline \multirow{4}{*}{1} & \multirow{4}{*}{$\begin{array}{l}\text { Regular fire drills } \\
\text { conducted in the } \\
\text { building }\end{array}$} & $\begin{array}{c}\text { Not } \\
\text { Aware }\end{array}$ & 214 & 95.5 \\
\hline & & $\begin{array}{c}\text { Not } \\
\text { Certain }\end{array}$ & 10 & 4.5 \\
\hline & & Aware & 0 & 0 \\
\hline & & Total & 224 & 100 \\
\hline \multirow{4}{*}{2} & \multirow{4}{*}{$\begin{array}{l}\text { Regular forums on } \\
\text { how to } \\
\text { appropriately } \\
\text { response to fire } \\
\text { outbreak exist in } \\
\text { the university }\end{array}$} & $\begin{array}{c}\text { Not } \\
\text { Aware }\end{array}$ & 134 & 59.8 \\
\hline & & $\begin{array}{c}\text { Not } \\
\text { Certain }\end{array}$ & 25 & 11.2 \\
\hline & & Aware & 65 & 29 \\
\hline & & Total & 224 & 100 \\
\hline \multirow{4}{*}{3} & \multirow{4}{*}{$\begin{array}{l}\text { Presence of } \\
\text { signage displaying } \\
\text { fire safety tips are } \\
\text { evident in the } \\
\text { building }\end{array}$} & $\begin{array}{c}\text { Not } \\
\text { Aware }\end{array}$ & 168 & 75 \\
\hline & & $\begin{array}{c}\text { Not } \\
\text { Certain }\end{array}$ & 3 & 1.3 \\
\hline & & Aware & 53 & 23.7 \\
\hline & & Total & 224 & 100 \\
\hline
\end{tabular}

The result in Table 4 revealed that a whopping majority $(95.5 \%)$ of the respondents are not aware if regular fire drills are conducted in the college building to imply that fire drills are hardly carried out in the building. Also, most $(59.8 \%)$ of the respondents attested that they are not aware of any regular forums organised by the university on fire safety issues. However, some $(29 \%)$ claim they are aware of such forum, whereas few $(11.2 \%)$ are not certain of their view. Again, a whopping majority (75\%) of the participants indicated that they are not aware of any fire safety tip signage displayed in the building. Generally, these findings imply that majority of the respondents are not being provided with regular information as they should by the management of the college building, on fire safety tips relevant for them to be able to respond appropriately in case of a fire outbreak in the building, contrary to fire safety standard practice.

\subsubsection{Users' Ability to Operate Common Fire Emergency Safety Devices}

To evaluate the ability of the users to operate common fire emergency safety devices expected in such a public building, once again the participants were made to choose one of the three possible options provided, which are: "Not Aware", "Not Certain" and "Aware". The result is presented in Table 5.

Table 5. Users Ability to Operate Common Fire Emergency Safety Devices

\begin{tabular}{ccccc}
\hline SN & $\begin{array}{c}\text { Firefighting and } \\
\text { Protection Devices }\end{array}$ & $\begin{array}{c}\text { Not } \\
\text { Aware } \\
(\mathbf{\%})\end{array}$ & $\begin{array}{c}\text { Not } \\
\text { Certain } \\
(\mathbf{\%})\end{array}$ & $\begin{array}{c}\text { Aware } \\
(\%)\end{array}$ \\
\hline 1 & Fire extinguishers & 39.6 & 7.7 & 52.7 \\
\hline 2 & Sand buckets & 39.6 & 7.7 & 52.7 \\
\hline 3 & Fire blankets & 40.1 & 7.7 & 52.2 \\
\hline 4 & Fire alarms & 75.3 & 2.2 & 22.5 \\
\hline 5 & Hose reels & 64.8 & 7.7 & 27.5 \\
\hline 6 & Wet risers & 86.4 & 1.2 & 12.4 \\
\hline 7 & Dry risers & 98.7 & 1.3 & 0 \\
\hline
\end{tabular}

The data in Table 5 on the ability of users to operate some common fire emergency safety devices, shows that while most of the respondents are aware of how to use majority of the common hand appliances (fire extinguishers, sand buckets and fire blankets), most of them are not aware of how to operate all the common full scale firefighting and protection systems (hose reels, dry risers and wet risers). This is understandable, as full scale firefighting and protection emergency systems are measures incorporated in buildings for the use of trained firefighting personnel and not for everyday users of such buildings. However, most (75.3\%) of the respondents are not aware of how to operate fire alarms which most users of the building should be able to operate in the event of a fire outbreak. Only some (22.5\%) indicated that they can operate it, while few $(2.2 \%)$ are not sure if they can operate 
it or not. This implies that in the event of a fire outbreak, while majority of the users might be able to locate and operate the firefighting and protection hand appliances, alerting users of the building through fire alarm systems will be a significant challenge. This is because apart from the finding that fire alarm systems were discovered not to be incorporated in the building, most of the users will not be able to operate them even if integrated in the structure.

\subsection{Discussion}

With reference to the first objective of the study which was to identify the fire emergency safety measures employed in the CLDS building, it was established that the active measures provided are only fire extinguishers and fire buckets, located at strategic positions along internal corridors on all floors of the buildings. Both the extinguishers and fire buckets are situated in visible locations within the building and conform to Toreki [30] submission, that such measures should be placed in visible and accessible positions, and painted red to enhance visibility. The passive measures observed were the use of fire walls and floors, fire exists, sizeable escape routes inside the building and sizable space around the building that can enable fire trucks to manoeuvre in emergency situations. This goes to show that some conscious planning and tangible design measures were put in place to prepare for fire emergency situations in the buildings as expected.

However, based on the second objective, which was to determine the adequacy of the fire emergency safety provisions in the building, the result indicated that the passive emergency protection measures are slightly inadequate, whereas the active measures are highly inadequate. The building falls short of complying with several fire safety requirements outlined in the National Building Code [27] of Nigeria for public buildings. The Code specified the provision of equipment such as: voice alarm systems, sprinklers, smoke detectors and public address systems on all floors of office buildings which are all absent in the CLDS building. However, a few regulations from the National Building Code were adhered to in the building. These include the provision of non-combustible exit stairways and fire extinguishers.

In general, the fire emergency safety provisions of the building are not justifiably sufficient and therefore adjudged not reasonably adequate. This goes to show that the preparedness of the college building towards combating fire is low. The broad implication of this result is that, the fire emergency measures in place in the building are not reasonably reliable for achieving the fundamental goal of fire protection in buildings, which is for the adequate protection of both lives and properties. This result agrees with the findings of Olufemi [7] who discovered that firefighting equipment are not adequate in most tertiary institutions in Nigeria. This finding also supports the view of Amaniampong, Ameyaw \& Akortsu [6] who noted that the role of the development of educational infrastructure in tertiary institutions is often ambivalent to the functionality of facilities during a fire outbreak. The authors noted that planning and building regulations often fail to prioritize the improvement of fire safety adequacy to increase the level of satisfaction obtained from using such environments.

The third objective was carried out to determine the awareness level of users of basic fire emergency safety protocol, while the fourth objective was conducted to ascertain to what extent are users of the building able to operate common fire emergency safety devices. The result indicated that though most of the respondents are aware of the location of the fire retardant systems in the building, majority of them do not know how to operate several common appliances. This result is in line with Ndetu \& Kaluyu [3] who discovered that most students are not able to put retardant systems to use in case of a fire outbreak. The fire safety emergency preparedness capacities of the users of the CLDS building are also worsened by the fact that majority of the respondents are not aware of the fire exits located in the building or any fire emergency number to call in case of a fire outbreak. The reason for this cannot be unconnected with the fact that fire drills are rarely conducted in the building, as none of the respondents indicated that they are aware of regular fire drill exercises in the building. To further worsen the plight of the users with regards to their preparedness towards effectively combating a fire outbreak in the building, most of the respondents are not also aware, if regular forums exist in the university for educating the university community on how to appropriately response to fire outbreaks in the institution. As fire signage were not noticed in the building, it was also not surprising that most of the respondents indicated that they are not aware of the presence of signage to display fire safety tips in the building. All these situations suggest that the fire emergency safety preparedness of the users of the building is also low.

According to Cote [24], fire emergency safety plans are important as they influence the level of preparedness in case of a fire disaster. Fire safety preparedness or the lack thereof affects the psyche of building occupants, especially in areas where there have been incessant cases of fire outbreaks [6]. Based on the general findings of the study, it is apparent that the fire safety emergency preparedness of the CLDS building is low, both from the angle of the active and passive fire safety measures provided and from the users' knowledge of basic fire emergency safety protocols. The general implication of the result is that the CLDS building and its users are not reasonably prepared to effectively combat a fire outbreak, particularly a major outbreak. In the event of such incident, it is most likely that the damage the fire will cause will be higher than in a situation where adequate precautionary measures are put in place in line with best practices, to avert, as well as combat the fire. Another implication of the current situation on fire 
emergency preparedness in the college building is that reasonable protection of both lives and properties cannot be guaranteed in the event of a fire outbreak in the building, contrary to the goal of the principles of fire emergency safety provisions in public buildings. There is therefore a need for more appropriate measures to be put in place in the building towards the reasonable protection of both lives and properties should a fire occur. As it is, the essence of having fire emergency safety measures in buildings cannot be fully realised with the current state of preparedness of both the building and its occupants in combating a fire incident. According to Sholanke, Adelowo and Gbotosho [46], it is important to holistically develop learning environments such that facilities are all-inclusively developed, so that everyone can experience and benefit from all aspects of education within academic environments.

\section{Conclusion}

The study investigated the fire emergency safety preparedness in the College of Leadership Development Studies building in Covenant University, Ota in Nigeria to establish how prepared the building and its users are towards combating a fire outbreak, with a view to identify areas for further improvements. The study found that the preparedness level of both the building and its users towards combating a fire outbreak is low. Several necessary active and passive fire emergency safety measures were not provided for in the building. Key active measures not provided for include, automatic fire detection devices, fire alarm systems, fire blankets and full scale firefighting measures such as hose reels, wet or dry risers, drenchers and sprinklers. Whereas notable among the passive measures missing in the building are, dampers, fire doors, fire signage and muster points. On the part of the users, the study established that, while majority of the respondents are aware of the location of the few emergency firefighting hand appliances provided in the building, most of them indicated that they are not aware of how to operate majority of the common fire emergency safety provisions. Most of the respondents also lacked the knowledge of several basic fire safety emergency protocols, to indicate that generally the fire emergency safety preparedness in the college building is low. Based on how the building is currently unequipped with inadequate fire emergency safety measures and used by occupants who mostly lack knowledge on basic fire emergency safety protocols, prompt and effective responsiveness to fire occurrences expected in such a building, cannot be guaranteed.

In general, the study highlighted the conditions required for public buildings, including academic buildings, to be adequately equipped to combat fire outbreaks. The specific contributions to knowledge of the study with regards to the fire emergency safety preparedness in the College of Leadership and Development Studies building in Covenant University include the establishment of empirical evidence on the following: the active and passive measures provided for; the adequacy of the said measures; the extent to which users of the building can operate basic fire emergency safety devices; and the level of users' awareness of common fire emergency safety protocols.

Based on the outcome of the study, the following recommendations are made in order to enhance the fire safety level in the college building: the building should be retrofitted with active and passive firefighting and protection measures found to be missing; all active firefighting devices should be checked regularly to ensure they are in good working order at all times; regular fire safety workshops and seminars should be carried out in the institution for the benefit of the university community; and regular fire drills should also be conducted in the building from time to time to help improve users awareness level on basic fire emergency safety protocols.

In addition, the research was conducted as a case study, which implies that the result cannot be generalised. Therefore, there is a need for similar studies to cover other academic buildings on the university campus. Such studies can also be conducted in other institutions of learning in Nigeria and around the world. Such studies will be useful feedback resources for building professionals towards the development of buildings with adequate built-in fire emergency safety provisions. Similar studies can also expand the scope to include opinions of other users of academic buildings, such as, postgraduate students, faculty, staff and visitors to provide an overall perspective on users' awareness level of fire safety protocols and their capacity to use basic fire emergency safety equipment in academic environments.

\section{Acknowledgements}

The authors wish to appreciate Covenant University for providing the facilities and the funding to conduct the research. The authors also acknowledge those whose intellectual materials were consulted in the course of conducting the research. Such persons have been duly cited in the work and their articles appropriately referenced in the reference section that follows.

\section{REFERENCES}

[1] M. J. Kihila. Fire Disaster Preparedness and Situational Analysis in Higher Learning Institutions of Tanzania . Journal of Disaster Risk Studies, Vol.9, No.1, 1-9, 2017. DOI: 10.4102 jamba.v9i1.311

[2] S. Huzayifa. An Investigation of Fire Emergency 
Preparedness in the Facaulty of Engineering in Utm in Johor Bahru School Joural, Vol. 19, No. 6, 1-127, 2019.

[3] K. D. Ndetu \& V. Kaluyu. Factors Influencing Fire Disaster Mangement Preparedness: A Case Study of Primary Schools in Makueni County, Kenya. European Journal of Education studies, Vol. , No. 6, 63-77, 2016.

[4] United States Federal Emergency Management Agency, National Preparedness Guidelines, Online Available from https://www.fema.gov/guidance (accessed Jan. 10, 2020).

[5] Fisher I, 58 Youths Die in Kenyan Dormitory, Online available from https://www.nytimes.com/2001/03/27/world /58-youths-die-in-kenyan-dormitoryfire.html (accessed Dec. 19, 2019).

[6] E. A. Amaniampong, S. Ameyaw \& W. Akortsu. Qualitative Adequacy of Students Hostels in Wa, Ghana. Civil Engineering and Architecture, Vol. 5, No. 6, 193-206, 2017. DOI: $10.13189 /$ cea.2017.050601

[7] A. Olufemi. Fire Extinguisher Management in OAU, Online available from https://www.premiumtimesng.com/regional/ ssouth-west/290494-after-three-fire-outbreaks-oau-students -demand-fire-extinguishers-from-university- (accessed Jan. 24, 2020).

[8] A. Pearson. The Importance of Fire Training for Employees, Online available from https://blog.astutis.com/2014/11/25/t he-importance-of-fire-extinguisher-training-for-employees (accessed Dec. 30, 2019).

[9] Florida Atlantic University, Fire Safety Manual, Online available from http://www.fau.edu/provost/files/facultyhan dbook11-12.pdf (accessed Dec. 22, 2019).

[10] J. Burtles \& K. Noakes-Fry. The Challlenge of Emergency Evacuation from High Rise Buildings. Online available from https://www.riskandresiliencehub.com/the-challenge-of-em ergency-evacuation-from-high-rise-buildings-and-even-one s-that-are-not-so-high-2/ (accessed Dec. 30, 2019).

[11] M. A. Hassanain \& A. N. Ashwal. An approach to Assess Fire Safety Requirements in Library Facilities. Emerald Journal, Vol. 23. No. 5/6, 239-252, 2005.

[12] S. Calams, What is Fire Made of?, Online available from https://www.firerescue1.com/firefighter-training/articles/wh at-is-fire-made-of-8GVclowtNF9mOGPm/ (accessed Dec. 29, 2019).

[13] G. J. Pausas \& E. J. Keeley. A Buring Story: The Role of Fire in the History of Life. Journal of BioScience, Vol. 59. No. 7, 593-601, 2009.

[14] E. Wayman. The Earliest Example of Hominid Fire. Online available from https://www.smithsonianmag.com/science-n ature/the-earliest-example-of-hominid-fire-171693652/ (accessed Jan. 5, 2020).

[15] K. Odegard. The History of Fire. Online available from https://jotul.com/int/home/the-history-of-fire (accessed Jan. 4, 2020).

[16] G. Proulx. Playing with Fire: Understanding Human Behaviour in Burning Buildings. American Society of Heating, Refrigerating and Air Conditioning Engineers (ASHRAE) Journal, Vol. 45, No. 7, 33-35, 2003.

[17] Occupational Safety and Health Act (OSHA) - A Malaysian
Law. Online available from https://www.osha.gov/SLTC/fir esafety/ (accessed Feb. 15, 2020).

[18] Merriam Webster Dictionary, Fire. Online available from https://www.merriam-webster.com/dictionary/fire (accessed Jun. 28, 2020).

[19] Z. Wang, R. Wei, J. He \& J. Wang. Melt dripping behaviour in the Process of Flame Spread over Energized Electrical Wire at Different Pressures. Fire and Materials International Journal, Vol. 44, No. 4, 7-12, 2018. DOI: 10.1002/fam.2764

[20] D. Harmon. What Causes Electrical Fires in the Home, Online available from https://dengarden.com/home-improv ement/What-Causes-Electrical-Fires-in-the-Home (accessed Jun. 28, 2020).

[21] D. Beaudrie. 7 Common Causes of House Fires and How to Prevent them. Online available from https://www.thespruce .com/causes-of-house-fires-1835107 (accessed Feb. 19, 2020).

[22] A. Adekunle, A. Asuquo, N. Essang, I. I. Umanah, K. E. Ibe \& A. B. Alo. Statistical Analysis of Electrical Fire Outbreaks in Buildings: Case Study of Lagos State, Nigeria. Journal of Sustainable Development Studies, Vol. 9, No. 1, 76-92, 2016. DOI: 10.1007/s00202-020-01028-0

[23] P. B. Anaglatey. Accra Continues to Record Fire Outbreaks. Accra: The Chronicle. Online available from http://www.scirj.org/papers-0717/scirj-P0717419.pdf (accessed Jan. 13, 2020).

[24] W. Boateng. Electricity Company of Ghana Explains Causes of Fire Outbreaks. Online available from https://www.ghanaweb.com/GhanaHomePage/NewsArchiv e/ECG-explains-causes-of-fire-outbreaks-263090 (accessed Jan. 25, 2020).

[25] D. Gold \& K. Koigi. Fire Protection Checklist. FINNIDA-ILO, Online available from http://ijettjournal.org /archive/ijett-v66p224 (accessed Jan. 18, 2020).

[26] A. Cote. Fire Protection Handbook, Quincy, Mass: NFPA, Online available from http://catalog.nfpa.org/Fire-Protectio n-Handbook-20th-Edition-P13860.aspx (accessed Jan. 28, 2020).

[27] National Building Code (2006). The Federal Republic of Nigeria National Building Code: First Edition; LexisNexis Butterworths

[28] M. Kapoor. Disaster Management. KCAA. 2007 Rules. New Delhi: Motilal Banaisidasi, Online available from https://www.ufs.ac.za/docs/librariesprovider22/disaster-ma nagement-training-and-education-centre-for-africa-(dimtec) -documents/dissertations/2300.pdf?sfvrsn=93fef821_2 (accessed Jun. 23, 2020).

[29] Marco Protection Systems. What is the Difference Between Active and Passive Fire Protection? Online available from https://www.marcofire.com/blog/what-is-the-difference-bet ween-active-and-passive-fire-protection/ (accessed Jan. 28, 2020).

[30] R. Toreki. Fire Safety and Fire Extinguishers. Online available from http://www.ilpi.com/safety/extinguishers.ht $\mathrm{ml}$ (accessed Jun. 23, 2020).

[31] A. E. Oke, S. A. Makanjuola \& A. O. Aiyetan. Assessment of Fire Safety Practices in Public Buildings in Western 
Nigeria. Online available from https://www.researchgate.ne t/publication/313850680_Assessment_of_fire_safety_practi ces_in_public_buildings_in_western_Nigeria (accessed Jun. $22,2020)$.

[32] R. Oden. Life Safety Issues with Exit Doors. Online available from https://www.locksmithledger.com/door-hard ware/article/10238156/life-safety-issues-with-exit-doors (accessed Feb. 16, 2020).

[33] Hong, A., How do Photoluminescent Exit Signs Work? Online available from https://medium.com/@weallight/how -do-photoluminescent-exit-signs-work-898aa0ca7c87 (accessed Jun. 22, 2020).

[34] D. Adler. Metric Handbook: Planning and Design Data. Oxford, Architectural Press, United Kingdom, 2005.

[35] A. B. Sholanke. Compliance of Academic Buildings of Selected Universities in Ogun State, Nigeria with Universal Design Parameters., Covenant University, Ota. PhD Thesis, Nigeria, 2019.

[36] A. B. Sholanke, A. B. Adeboye \& O. A. Alagbe. Design Solutions Creating Barriers to Achieving Universal Design Compliance of Academic Buildings in Universities in Nigeria. International Journal of Civil Engineering and Technology (IJCIET), Vol. 10, No. 1, 671-690, 2019.

[37] The Brick Industry Association, Fire Resistance of Brick Masonry, Online available from http://www.gobrick.com/d ocs/default-source/read-research-documents/technicalnotes/ 16-fire-resistance-of-brick-masonry.pdf (accessed Jun. 26, 2020).

[38] National Institute of Standards and Technology. Fire. Online available from https://www.nist.gov/topics/fire (accessed Jun. 15, 2020).
[39] British Woodworking Federation. Fire Doors. Online available from https://www.bwf.org.uk/choose-wood/fire-d oors/ (accessed Jan. 24, 2020).

[40] J. Dalto. OSHA Fire Extinguisher Mounting Height, Placement \& Signage Requirement. Online available from https://www.convergencetraining.com/blog/osha-fire-exting uisher-mounting-height-placement-signage-requirements (accessed Jan. 24, 2020).

[41] L. Hopper. Landscape Architectural Graphic Standards. John Wiley \& Sons, Inc., United Kingdom, 2007.

[42] Unifour Fire \& Safety. How Many Fire Extinguishers does my Building Need? Online available from https://www.unifourfire.com/blog/how-many-fire-extinguis hers (accessed Jan. 24, 2020).

[43] A. O. Oluwunmi. Students Satisfaction with Academic Facilities in Private Universities in Ogun State, Nigeria., Covenant University, Ota, Ogun State. PhD Thesis, Nigeria, 2014.

[44] National Concrete Masonry Assocation. Fire Resistance Ratings of Concrete Masonry Assemblies. Online available from https://ncma.org/resource/fire-resistance-ratings-ofconcrete-masonry-assemblies/ (accessed Jun. 26, 2020).

[45] M. Kironji. Assessment of Fire Escape Routes in Commercial High Rise Buildings in the Nairobi CBD, Kenya. International Journal of Scientific and Research Publications, Vol. 5, No. 10, 50-51, 2015.

[46] Sholanke A. B., Adelowo I. E. \& Gbotosho J. O. Compliance of High-rise Buildings Vertical Accessibility Components with Universal Design Strategies: A Case Study of Covenant University, Ota, Nigeria. Civil Engineering and Architecture, Vol. 8, No. 5, pp. 735 - 749, 2020. DOI: 10.13189/cea.2020.080501. 